\title{
Disulfide polymer grafted porous carbon composites for heavy metal removal from
} stormwater runoff

Ko, Dongah; Mines, Paul D.; Jakobsen, Mogens Havsteen; Yavuz, Cafer T.; Hansen, Hans Chr B.; Andersen, Henrik R.

Published in:

Chemical Engineering Journal

Link to article, DOI:

10.1016/j.cej.2018.04.192

Publication date:

2018

Document Version

Peer reviewed version

Link back to DTU Orbit

Citation $(A P A)$ :

Ko, D., Mines, P. D., Jakobsen, M. H., Yavuz, C. T., Hansen, H. C. B., \& Andersen, H. R. (2018). Disulfide polymer grafted porous carbon composites for heavy metal removal from stormwater runoff. Chemical Engineering Journal, 348, 685-692. https://doi.org/10.1016/j.cej.2018.04.192

\section{General rights}

Copyright and moral rights for the publications made accessible in the public portal are retained by the authors and/or other copyright owners and it is a condition of accessing publications that users recognise and abide by the legal requirements associated with these rights.

- Users may download and print one copy of any publication from the public portal for the purpose of private study or research.

- You may not further distribute the material or use it for any profit-making activity or commercial gain

- You may freely distribute the URL identifying the publication in the public portal 


\section{Accepted Manuscript}

Disulfide polymer grafted porous carbon composites for heavy metal removal from stormwater runoff

Dongah Ko, Paul D. Mines, Mogens H. Jakobsen, Cafer T. Yavuz, Hans Chr. B. Hansen, Henrik R. Andersen

PII: S1385-8947(18)30765-4

DOI: https://doi.org/10.1016/j.cej.2018.04.192

Reference:

CEJ 18992

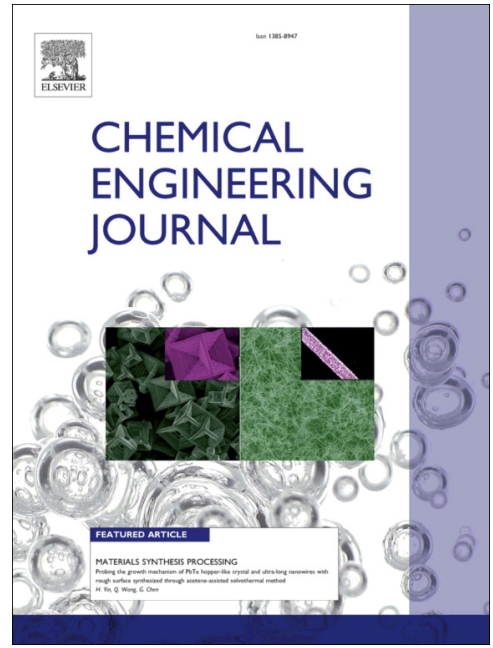

To appear in:

\section{Chemical Engineering Journal}

Received Date: $\quad 10$ January 2018

Revised Date: $\quad 26$ April 2018

Accepted Date: $\quad 27$ April 2018

Please cite this article as: D. Ko, P.D. Mines, M.H. Jakobsen, C.T. Yavuz, r.B. Hansen, H.R. Andersen, Disulfide polymer grafted porous carbon composites for heavy metal removal from stormwater runoff, Chemical Engineering Journal (2018), doi: https://doi.org/10.1016/j.cej.2018.04.192

This is a PDF file of an unedited manuscript that has been accepted for publication. As a service to our customers we are providing this early version of the manuscript. The manuscript will undergo copyediting, typesetting, and review of the resulting proof before it is published in its final form. Please note that during the production process errors may be discovered which could affect the content, and all legal disclaimers that apply to the journal pertain. 


\section{Disulfide polymer grafted porous carbon composites}

\section{for heavy metal removal from stormwater runoff}

Dongah Ko ${ }^{a} *$, Paul D. Mines ${ }^{b}$, Mogens H. Jakobsen ${ }^{b}$, Cafer T. Yavuz ${ }^{c}$, Hans Chr. B. Hansen ${ }^{d}$, Henrik R. Andersen ${ }^{a}$

${ }^{a}$ Department of Environmental Engineering, Technical University of Denmark, Bygningstorvet 115, 2800 Kgs. Lyngby, Denmark.

${ }^{\mathrm{b}}$ Department of Micro- and Nanotechnology, Technical University of Denmark, Ørsteds Plads, 345B, 2800 Kgs. Lyngby, Demark.

${ }^{c}$ Graduate School of EEWS, Korea Advanced Institute of Science and Technology (KAIST), Daejeon 34141, Republic of Korea.

${ }^{\mathrm{d}}$ Department of Plant and Environmental Sciences, University of Copenhagen, Frederiksberg, Thorvaldsensvej 40, 1871 Frederiksberg C, Denmark.

* Corresponding author. Department of Environmental Engineering, Technical University of Denmark, Bygningstorvet 115, 2800 Kgs. Lyngby, Denmark.

E-mail address: koda830@gmail.com (Dongah Ko).

Keywords: Acyl chlorination surface modification, polymer grafted carbon, stormwater runoff, heavy metal removal, cadmium 


\section{Abstract}

The emerging concern of heavy metal pollution derived from stormwater runoff has triggered a demand for effective heavy metal sorbents. To be an effective sorbent, high affinity along with rapid sorption kinetics for environmental relevant concentrations of heavy metals is important. Herein, we have introduced a new composite suitable for trace metal concentration removal, which consists of cheap and common granular activated carbon covered with polymers containing soft bases, thiols, through acyl chlorination (DiS-AC). Material characterization demonstrated that the polymer was successfully grafted and grown onto the surface of the carbon substrate. The distribution coefficient for $\mathrm{Cd}^{2+}$ bonding was $89 \cdot 10^{3} \mathrm{~L} / \mathrm{kg}$ at a solution concentration of $0.35 \mathrm{mg} / \mathrm{L}$, which is notably higher than sorption affinities for $\mathrm{Cd}^{2+}$ seen in conventional sorbents. The sorption isotherm is well described by the Freundlich isotherm and within an hour, half of the initial trace $(0.2 \mathrm{mg} / \mathrm{L})$ concentration of $\mathrm{Cd}^{2+}$ was removed by the DiS-AC at a sorbent loading of $2 \mathrm{~g} / \mathrm{L}$. Therefore, the novel material DiS-AC promises to be an ideal candidate for filters treating stormwater runoff.

\section{Introduction}

Climate change has brought frequent, unexpected rainfall events that come along with the arising problem of stormwater runoff and subsequent drainage overflows [1]. A wide range of hazardous pollutants are released from these non-point sources and may cause epidemic problems to populations [2]. Among the pollutants, heavy metals are a notable problem, not only from urban stormwater runoff, but also in agricultural runoff. Urban stormwater runoff has limited natural infiltration due to the paved surface in cities, and thus a considerable amount of lead, copper, cadmium, and zinc from roads are washed off [3,4]. Additionally, roofs of buildings and atmospheric deposits also exacerbate heavy metal contamination during rainfall events [1,5]. Agricultural runoff also presents noticeable heavy metal pollution; in particular, heavy metals are a 
well-known problem in Europe and Asia due to the widespread heavy metal contamination of phosphate fertilizers [6,7]. Heavy metals are persistent, easily accumulated in biota, and result in adverse impacts on the human body. According to previous studies, heavy metal concentrations in stormwater runoff often exceed the emission limit values [8,9]. Even though there are already many proven existing ways of removing heavy metals from source waters, uncertainties revolving around stormwater runoff, such as the irregular and often poorly controlled flow or unpredictable concentrations of pollutant contained within will persist. Thus, decontamination of heavy metals from stormwater runoff has been extensively studied and different applications developed, such as wet detention ponds, filtration, and trapping in underground catchment basins. Wet detention ponds are widely applied in urban outskirts due to its simplicity, providing higher hydraulic retention times by buffering runoff flow during storm events [10]. However, wet detention ponds are hard to use in urban areas, as they require a large footprint. Therefore, catchment basins and filtration systems, which are relatively compact, are commonly used in cities. For heavy metals, removal by adsorption is proven to be an optimal technique compared to other mechanisms for efficient treatment of stormwater runoff $[11,12]$. Adsorption also provides for low investment costs due to the capability of treating large volumes of runoff within short time periods $[12,13]$. The most commonly used sorbents for removing heavy metals are sand, zeolite, and activated carbon [12]; however, applicability of these sorbents is limited when the treatment procedure needs instant removal of the pollutant coupled with high efficiency. Ideally, sorbents for contaminants in stormwater runoff should exhibit high selectivity and rapid sorption kinetics, as well as sufficient sorption capacity to increase the life length of the filter material. In recent years, a new generation of highly porous covalently bonded organic polymers that are extremely robust have been developed. These sorbents have been used for gas capture [14-16], solvent uptake [17], and groundwater remediation [18]. In our previous study [19], we have introduced a disulfide linked 
polymer network material, that involves thiol groups combined with triazine rings. In virtue of its chemical functionality, high sorption selectivity for soft Lewis acid heavy metal ions in the presence of earth metal ions was achieved [20]. Moreover, the sorption kinetics and metal sorption capacity was proven to be sufficient for use in stormwater runoff. The main challenge for using polymers in treatment filters is their small grain size, less than $50 \mu \mathrm{m}$, which may lead to hydraulic pressure overload and massive amounts of grain loss during the process.

In this study, a novel composite was introduced by grafting dangling thiol handles on the backbone of cheap and common granular activated carbon (DiS-AC) through acyl chloride surface modification. The successful polymer grafting was confirmed through extensive physical and chemical characterizations. Moreover, the composites exhibit high sorption affinity along with rapid kinetics, which can then be retrofitted on to common filtration column treatment systems for stormwater runoff.

\section{Material and methods}

\subsection{Materials}

Granular activated carbon (GAC, 2-3 mm particle grade) was purchased from Samchun Chemical Co. Nitric acid (60\%) and sulfuric acid (47\%), thiol chloride (99\%), dimethylformamide, N,Ndiisopropylethylamine, cysteamine, sodium hydroxide, thiocyanuric acid, iodine, and potassium iodide were obtained from Sigma-Aldrich. Aqueous solutions of cadmium were prepared from 1000 mg cadmium standard solution $\left(\mathrm{CdCl}_{2}\right.$ in $\mathrm{H}_{2} \mathrm{O}$, Titrisol). All chemicals were used as received, unless otherwise stated. As a reference material, disulfide polymer was prepared by following the procedure previously published [19].

\subsection{Surface modification of GAC}

The surface modification processes were conducted in four steps, those being GAC oxidation, acyl chlorination [21], linear thiol attachment, and ultimately disulfide linked polymer grafting onto the 
substrate surface. Firstly in the aforementioned step processes, the GAC oxidation was performed with a 3:1 mixture of $\mathrm{HNO}_{3}$ and $\mathrm{H}_{2} \mathrm{SO}_{4}$ for $24 \mathrm{~h}$ at room temperature to form carboxylic groups on the GAC surface. Secondly, acyl chlorination was achieved by stirring the oxidized GAC in dichloromethane while thionyl chloride was slowly added into the solution under $\mathrm{N}_{2}$ atmosphere, in order to prevent hydrolysis of the newly formed acyl chloride groups; the solution was mixed under reflux for $24 \mathrm{~h}$ at $35^{\circ} \mathrm{C}$. Subsequently, the solvent was evaporated by rotary evaporator at $200 \mathrm{mbar}$ of vacuum, followed immediately by a linear thiol attachment step. The thiol attachment was done by adding a mixture of $2 \mathrm{mmol}$ of cysteamine dissolved in $180 \mathrm{~mL}$ of dimethylformamide to the acyl chloride activated GAC, followed by dropwise addition of $5.6 \mathrm{mmol}$ of N,Ndiisopropylethylamine. After $24 \mathrm{~h}$ of stirring at $80{ }^{\circ} \mathrm{C}$, the cysteamine treated GAC was dried in vacuum at $80{ }^{\circ} \mathrm{C}$ for $12 \mathrm{~h}$ and dispersed again into $150 \mathrm{~mL}$ of sodium hydroxide solution with 3 mmol of trithiocyanuric acid for the last step. A strong oxidant containing an excess amount of iodine and potassium iodide was added dropwise into the mixture, while a temperature of $0{ }^{\circ} \mathrm{C}$ was maintained, until the mixture became a homogeneous solution; then, it was stirred overnight at room temperature. Finally, the surface modified composite (DiS-AC) was obtained and dried at $80{ }^{\circ} \mathrm{C}$ in a vacuum oven. 

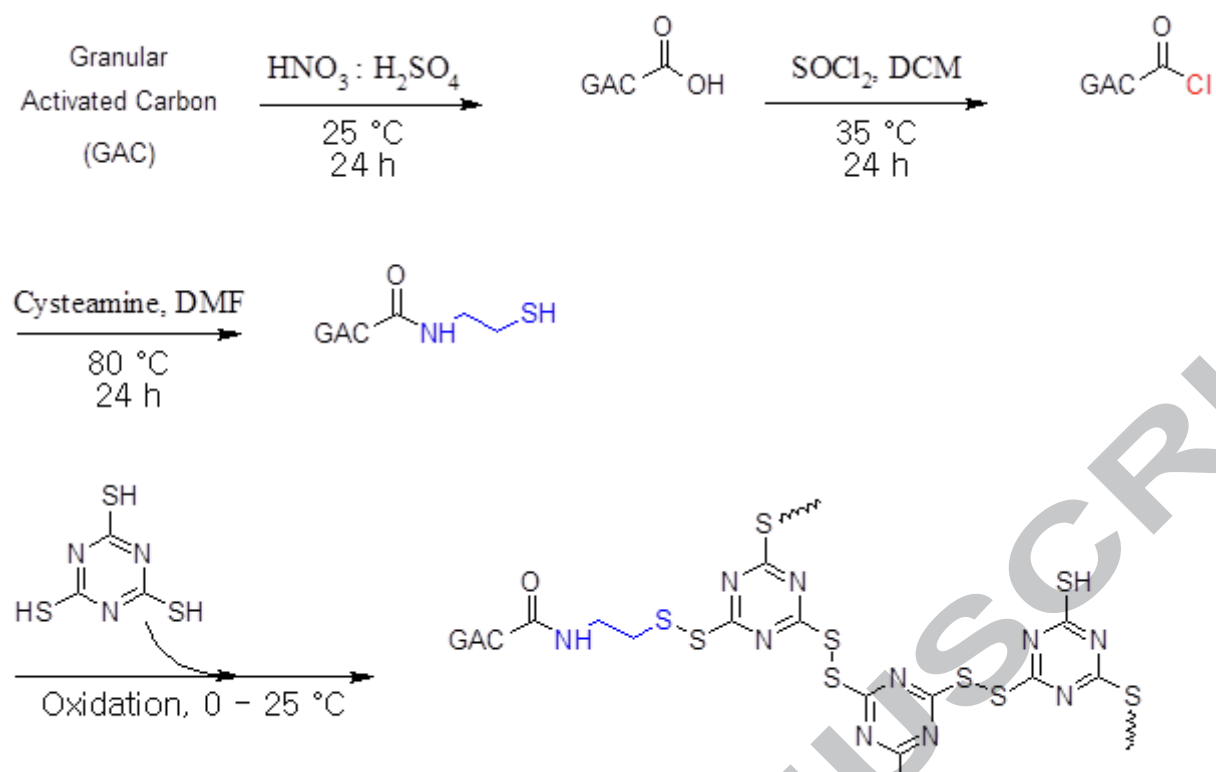

Figure 1. The step-wise procedure of DiS-AC synthesis. Initially, bare GAC is oxidized and modified through acyl chlorination. Afterwards, cysteamine is attached to the surface. Finally, disulfide polymer grafting has been implied on the cysteamine treated GAC.

\subsection{Characterization of the disulfide-linked polymer grafted activated carbon (DiS-AC)}

Various characterization techniques were implemented on the materials produced throughout this study. Scanning electron microscopy (SEM, Quanta FEG 200 ESEM, FEI) was employed to observe the morphology of the materials and the Brunauer-Emmett-Teller (BET) surface area was measured by $\mathrm{N}_{2}$ physisorption (3Flex, Micromeritics) after degassing the sample overnight under vacuum at $80^{\circ} \mathrm{C}$ prior to measurement. Elemental analysis (EA, Vario Macro Cube, Elementar) was used to measure and calculate the composition of the materials, namely, carbon, nitrogen, and sulfur. X-ray photoelectron spectroscopy (XPS, K-Alpha, Thermo Scientific, data deconvolution was done by Thermo Avantage Software) was employed in order to determine the surface elemental profiles of the materials; samples were analyzed under vacuum with a monochromated Al-K $\alpha \mathrm{X}$-ray source and an X-ray spot size of $400 \mu \mathrm{m}$. Thermo-gravimetric analysis (TGA, Discovery TGA, TA Instruments) was employed to evaluate the robustness and thermal stability of the materials, and 
subsequently coupled with Fourier-transform infrared spectroscopy (TGA-FTIR, Nicolet iS10, Thermo Scientific) to determine the functional groups degassed off samples during analysis.

\subsection{Sorption kinetics studies}

Three different cadmium concentrations were selected for determining the sorption kinetics of DiSAC. All tests were conducted in triplicate, in addition to a control test. Firstly, $40 \mathrm{~mL}$ of $0.2,0.35$, and $0.5 \mathrm{mg} / \mathrm{L}$ cadmium chloride solution mixed with $3 \mathrm{mM}$ of $\mathrm{NaHCO}_{3}$ buffer were placed into polyethylene conical centrifuge tubes and adjusted to approximately a $\mathrm{pH}$ of 8 by addition of $1 \mathrm{M}$ $\mathrm{HNO}_{3}$. The sample $\mathrm{pH}$ was stabilized for $1 \mathrm{~h}$ and initial samples were taken from the centrifuge tubes. Afterwards, $80 \mathrm{mg}$ of DiS-AC were added to each centrifuge tube and sampling was performed at $2 \mathrm{~min}, 10 \mathrm{~min}, 1 \mathrm{~h}, 4 \mathrm{~h}$, and $24 \mathrm{~h}$. Each sample was centrifuged $(1690 \mathrm{~g})$, then $1.5 \mathrm{~mL}$ of supernatant was collected and then acidified with $20 \mu \mathrm{l}$ of $\mathrm{HNO}_{3}$. Cadmium concentration was determined by graphite furnace atomic absorption spectrometer (GFAAS, Perkin Elmer, PinAAcle 900Z; LOD $0.1 \mu \mathrm{g} / \mathrm{L})$.

\subsection{Sorption as a function of $\mathrm{pH}$}

The effect of $\mathrm{pH}(6-8)$ on cadmium sorption to DiS-AC was scrutinized with the following procedure with replicates. A solution containing $10 \mathrm{~mL}$ of $0.5 \mathrm{mg} / \mathrm{L}$ cadmium chloride solution mixed with $3 \mathrm{mM} \mathrm{NaHCO} 3$ buffer was adjusted to the desired $\mathrm{pH}$ by addition of $1 \mathrm{M} \mathrm{HNO}_{3}$. The initial sample was collected after $1 \mathrm{~h}$ of $\mathrm{pH}$ stabilization, and then $20 \mathrm{mg}$ of DiS-AC were added and shaken, and samples were taken after $1 \mathrm{~h}$ and $24 \mathrm{~h}$. All samples were centrifuged and acidified with $20 \mu \mathrm{l}$ of $\mathrm{HNO}_{3}$, as described above. Samples were kept at $4{ }^{\circ} \mathrm{C}$ until measurement and cadmium concentrations were determined, as described above.

\subsection{Maximum sorption capacity and sorption isotherm studies}


Sorption isotherms were determined using four different cadmium concentrations with different DiS-AC dose (SI, Table A.1). Tests followed the same procedure as described above, except for the sampling times, which were $0 \mathrm{~h}$ and $24 \mathrm{~h}$. Cadmium concentrations were determined as described above.

\subsection{Sorption kinetics and isotherm fitting}

To describe the sorption kinetics, both pseudo first-order and second-order kinetics models were tested. Pseudo first-order kinetics, suggested by Lagergren (1989) [22] were used for fitting the sorption kinetics using the linear form, of which is formulated as:

$$
\ln \left(\mathrm{q}_{\mathrm{e}}-\mathrm{q}_{\mathrm{t}}\right)=\ln \mathrm{q}_{\mathrm{e}}-\mathrm{k}_{1} \mathrm{t}
$$

Where, $\mathrm{q}_{\mathrm{e}}$ and $\mathrm{q}_{\mathrm{t}}$ are the amounts of metal ions adsorbed $(\mathrm{mg} / \mathrm{g})$ at equilibrium and time $\mathrm{t}$, and $\mathrm{k}_{1}$ is the rate constant of the sorption $(1 / \mathrm{min})$.

The next sorption kinetics model, given by Ho and McKay (1999) [23], applied pseudo secondorder kinetics, expressed as:

$$
\frac{\mathrm{t}}{\mathrm{q}_{\mathrm{t}}}=\frac{1}{\mathrm{k}_{2} \mathrm{qe}^{2}}+\left(\frac{1}{\mathrm{q}_{\mathrm{e}}}\right) \mathrm{t}
$$

Where, $\mathrm{k}_{2}$ is the rate constant $(\mathrm{g} / \mathrm{mg} \cdot \mathrm{min})$ [23].

Sorption isotherm data were fitted by the Langmuir isotherm:

$$
\mathrm{q}_{\mathrm{e}}=\frac{\mathrm{q}_{\mathrm{m}} \mathrm{a}_{\mathrm{L}} \mathrm{C}_{\mathrm{e}}}{1+\mathrm{a}_{\mathrm{L}} \mathrm{C}_{\mathrm{e}}}
$$

where, $\mathrm{q}_{\mathrm{m}}$ is the maximum sorption capacity $(\mathrm{mg} / \mathrm{g}), \mathrm{C}_{\mathrm{e}}$ is the equilibrium concentration of the adsorbate in solution $(\mathrm{mg} / \mathrm{L})$, and $\mathrm{a}_{\mathrm{L}}$ is the Langmuir affinity constant $(\mathrm{L} / \mathrm{mg})$.

The data were also fitted by the Freundlich isotherm model:

$$
\mathrm{q}_{\mathrm{e}}=K_{F} C_{e}^{1 / n}
$$

where, $\mathrm{K}_{\mathrm{F}}$ is the Freundlich constant and $1 / \mathrm{n}$ is the heterogeneity factor.

The distribution coefficient for heavy metal bonding to the sorbent is given by [24]: 


$$
\mathrm{K}_{\mathrm{d}} \triangleq \frac{C_{S}}{C_{w}}=\frac{C_{i}-C_{e}}{C_{e}} \times \frac{V}{m}
$$

Where, $C_{i}$ is initial concentration of cadmium in aqueous solution, $C_{e}$ is the equilibrium concentration of cadmium in solution $(\mathrm{mg} / \mathrm{L}), \mathrm{V}(\mathrm{mL})$ the volume of solution, and $\mathrm{m}$ the mass of Sorbent $(\mathrm{g})$.

\section{Results and discussion}

\subsection{Physical properties of the DiS-AC materials}

First evidence of the successful attachment of DiS-AC was gathered using scanning electron microscopy (SEM). The structure of bare GAC (Figure 2a, c) exhibits a random and amorphous porous nature commonly found in all GACs [25]. However, after the surface modification and grafting of the polymer, the pores of GAC are substantially covered by polymer networks, as is visualized by the observed coating effect seen in SEM imaging (Figure 2b, d).

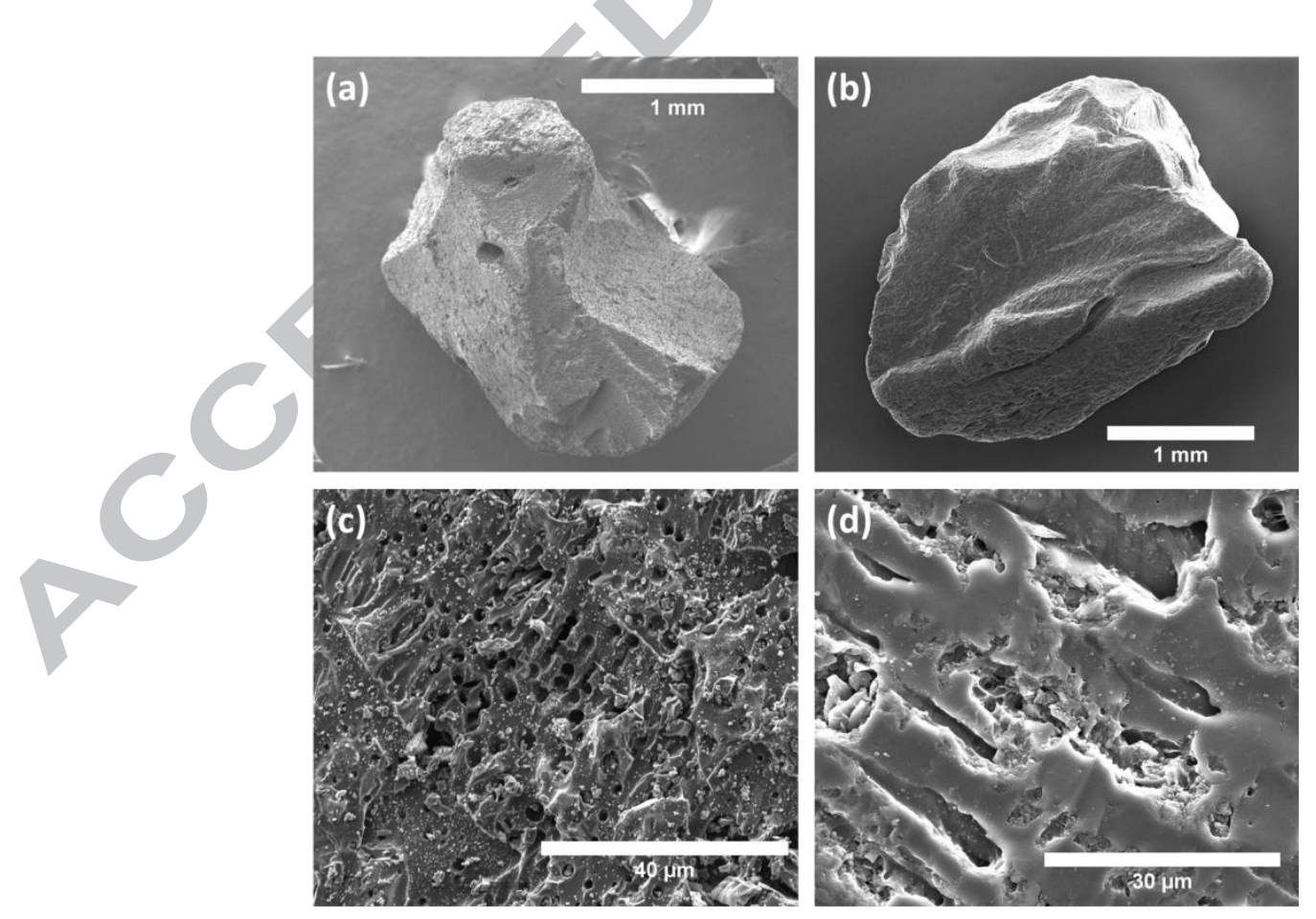

Figure 2. Scanning electron microscopy images of (a) overview morphology of GAC (b) overview morphology of DiS-AC (c) GAC surface and (d) DiS-AC surface. 
The DiS-AC Brunauer-Emmett-Teller (BET) surface area was determined to be $674 \mathrm{~m}^{2} / \mathrm{g}$, while the bare GAC possessed a slightly higher BET surface area of $943 \mathrm{~m}^{2} / \mathrm{g}$, indicating that the polymers have infiltrated and somewhat covered the porosity of the GAC. It is important to note that even though the grafted polymers appear to be blocking a discernible amount of pores of the GAC, there is still quite a high surface area remaining, due primarily to the porosity of polymer network itself.

\subsection{Elemental composition and surface chemistry of the DiS-AC}

The overall chemical composition was determined using elemental analysis (EA), finding that the DiS-AC consists of approximately $77.2 \%$ carbon, $1.5 \%$ nitrogen, and $1.4 \%$ sulfur. Assuming that there is a monomer unit of $\mathrm{C}_{6} \mathrm{ON}_{4} \mathrm{~S}_{4} \mathrm{H}_{5}$ in the polymer, then the measured contents of nitrogen and sulfur corresponds to a content of $4 \%$ (by mass) of the polymer in the GAC, which is compatible with the experimental observation weight difference measured between bare GAC and DiS-AC. Surface elemental characterization of the different DiS-AC or GAC preparations was achieved using X-ray photoelectron spectroscopy (XPS). With a material penetration depth of 5-10 nm, XPS provides a convenient measure for the elemental make-up of specifically the surface of a particular material, making this an ideal method for confirming that polymers are grafted to the GAC surface. XPS determined that the carbon substrate surface (Figure 3a) is primarily carbon (92\%) with a minor amount of defects contained in the form of oxygen $(8 \%)$ (Table 1). Acid oxidized carbon substrate expectedly contains slightly more oxygen $(+2.4$ to $10.4 \%)$, cysteamine $\left(\mathrm{C}_{2} \mathrm{H}_{7} \mathrm{NS}\right)$ grafted carbon substrate introduces the presence of nitrogen (2.6\%) and sulfur (0.9\%), and finally DiS-AC (Figure 3b) yields slightly higher nitrogen (3.6\%) and sulfur (1.0\%) quantities due to the added presence of thiocyanuric acid monomer polymerized with cysteamine (Table 1). 
Table 1. Surface atomic percentages of the different steps of the surface modified GAC, as determined by XPS.

\begin{tabular}{lcccc}
\hline Element & GAC & GAC-oxidized & GAC-cysteamine & DiS-AC \\
\hline$C$ & 92.0 & 89.6 & 83.9 & 80.5 \\
$O$ & 8.0 & 10.4 & 9.8 & 9.5 \\
$N$ & - & - & 2.6 & 3.6 \\
$S$ & - & - & 0.9 & 1.0 \\
Other & - & - & 2.9 & 5.3 \\
\hline
\end{tabular}

In order to gain further insight into the nature of the grafted polymer to the carbon substrate surface, a technique known as ion-etching was employed with the XPS instrument, in order to consecutively strip away layers off the surface of a material to expose underlying components. The ion-etching removes on average $50 \mathrm{~nm}$ of material from the surface of the sample being analysed. In particular, the sulfur S2p region was delved into and the associated sulfur chemistry was elucidated throughout subsequent layers (Figures 3c, d). Figure 3c illustrates the changing nature of the sulfur chemistry as layers are ion-etched off the surface. Figure $3 d$ gives the deconvoluted peaks seen in the depth profile, with four commonly observed peaks present [26,27]. The two primary peaks are attributed to disulfide S-S $(163.9 \mathrm{eV})$ and sulfur oxide S-O $(168.4 \mathrm{eV})$ while the two secondary peaks may be referred to S-C (165.4 eV) and S-H $(163.2 \mathrm{eV})$; with the sulfur oxide groups very much present at the surface and quickly disappearing in the underlying layers. Therefore, XPS layer analysis proved that the surface of the material is covered by sulfur containing polymer. 

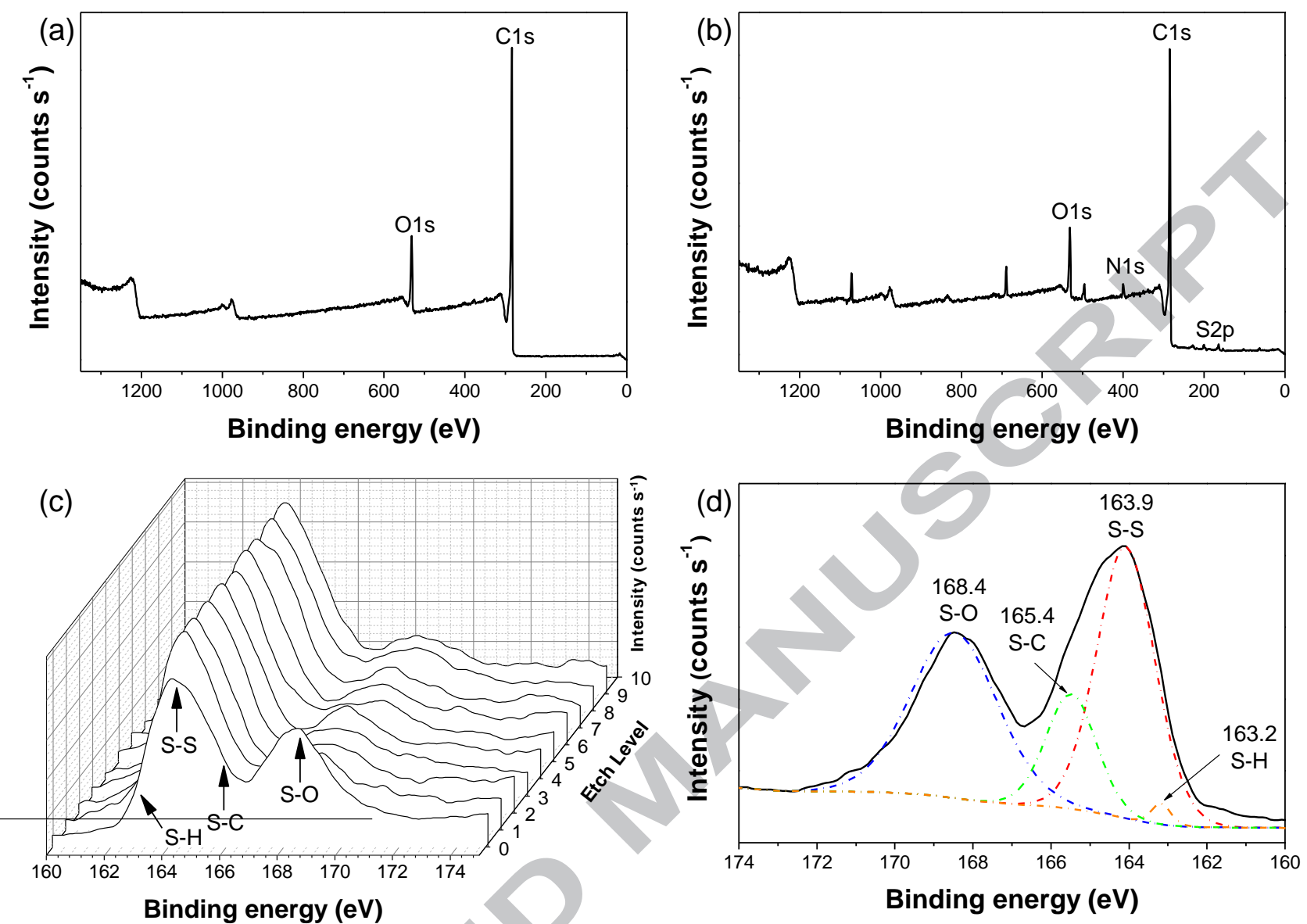

Figure 3. X-ray photoelectron spectra. (a) Bare GAC survey scan. (b) Polymer grafted DiS-AC survey scan. (c) Depth profile for ion etched S2p scans for DiS-AC (note that the x-axis has been reversed to better display peak variation). (d) Peak deconvolution of S2p scan etch-0 (before etching took place) for DiS-AC.

\subsection{Thermo-gravimetric analysis (TGA).}

In order to determine the robustness and thermal stability of the produced materials, thermogravimetric analysis (TGA) was run on bare GAC and DiS-AC. Bare GAC demonstrated an overall drop in weight by roughly $13 \%$ at temperature rising from 30 to $900{ }^{\circ} \mathrm{C}$, which is in agreement with a previous study of GAC surface modification using the same carbon substrate [21]; while DiS-AC resulted in an overall drop in weight by roughly $28 \%$ over the same temperature range. 


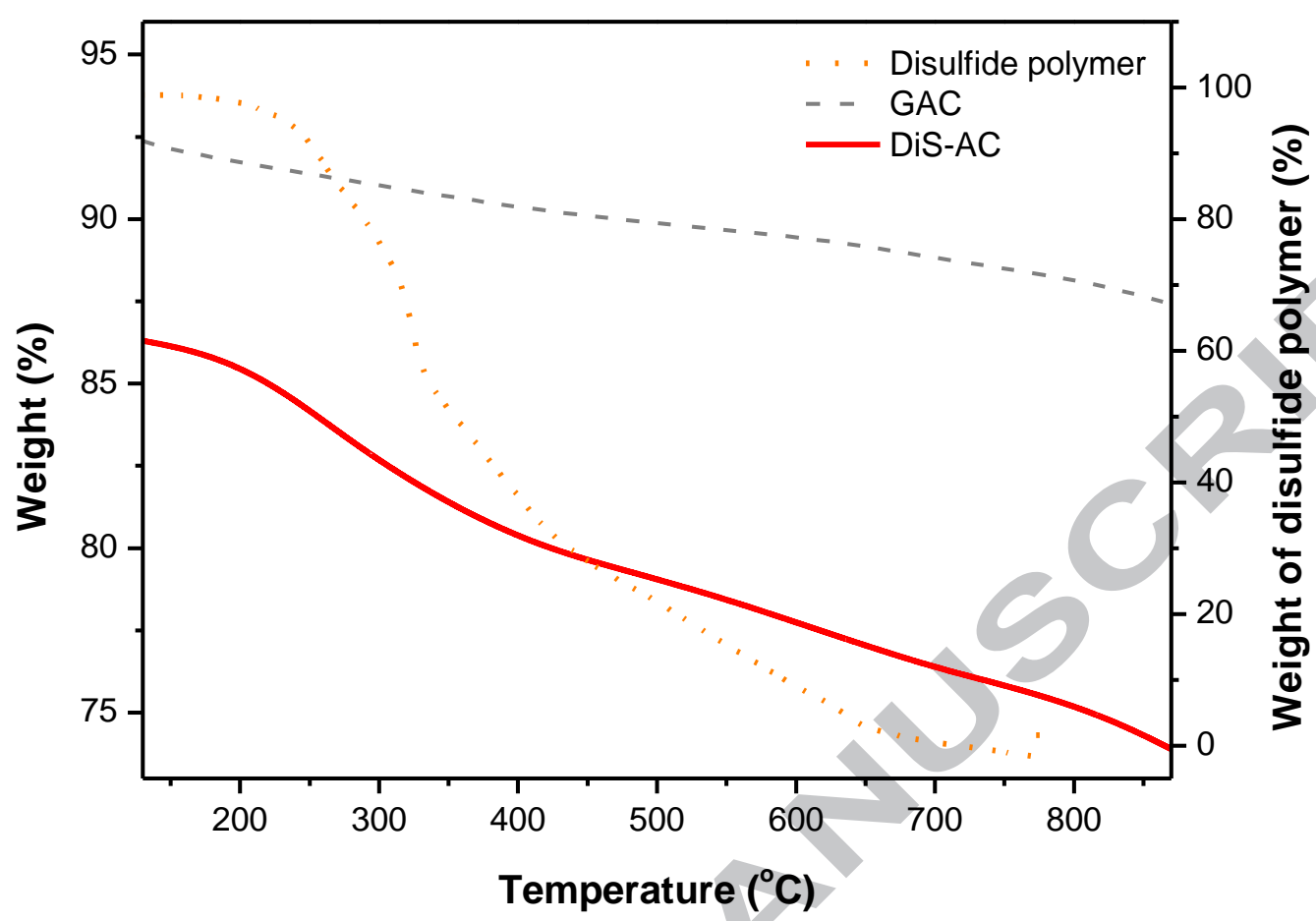

Figure 4. Thermo-gravimetric analysis of bare GAC (dashed line), the pure disulfide polymer (dotted line), and the grafted polymer DiS-AC (solid line).

It should be noted that there is an observable correlation in the disulfide polymer TGA curves and the grafted DiS-AC curves, in that there are similar mass loss trends at similar temperature profiles. It can be inferred that this indicates that the same material is being vaporized and degassed in both materials. Moreover, the weight loss of DiS-AC due to the polymer thermal degradation up to $250{ }^{\circ} \mathrm{C}$ is approximately $6 \%$, which is similar to the calculated empirical grafted polymer percentage, i.e. $4 \%$. For further confirmation, FTIR measurement was coupled with the TGA offgas stream (TGA-FTIR) to qualitatively characterize those materials being degasses during TGA analysis, see Figure 5. 


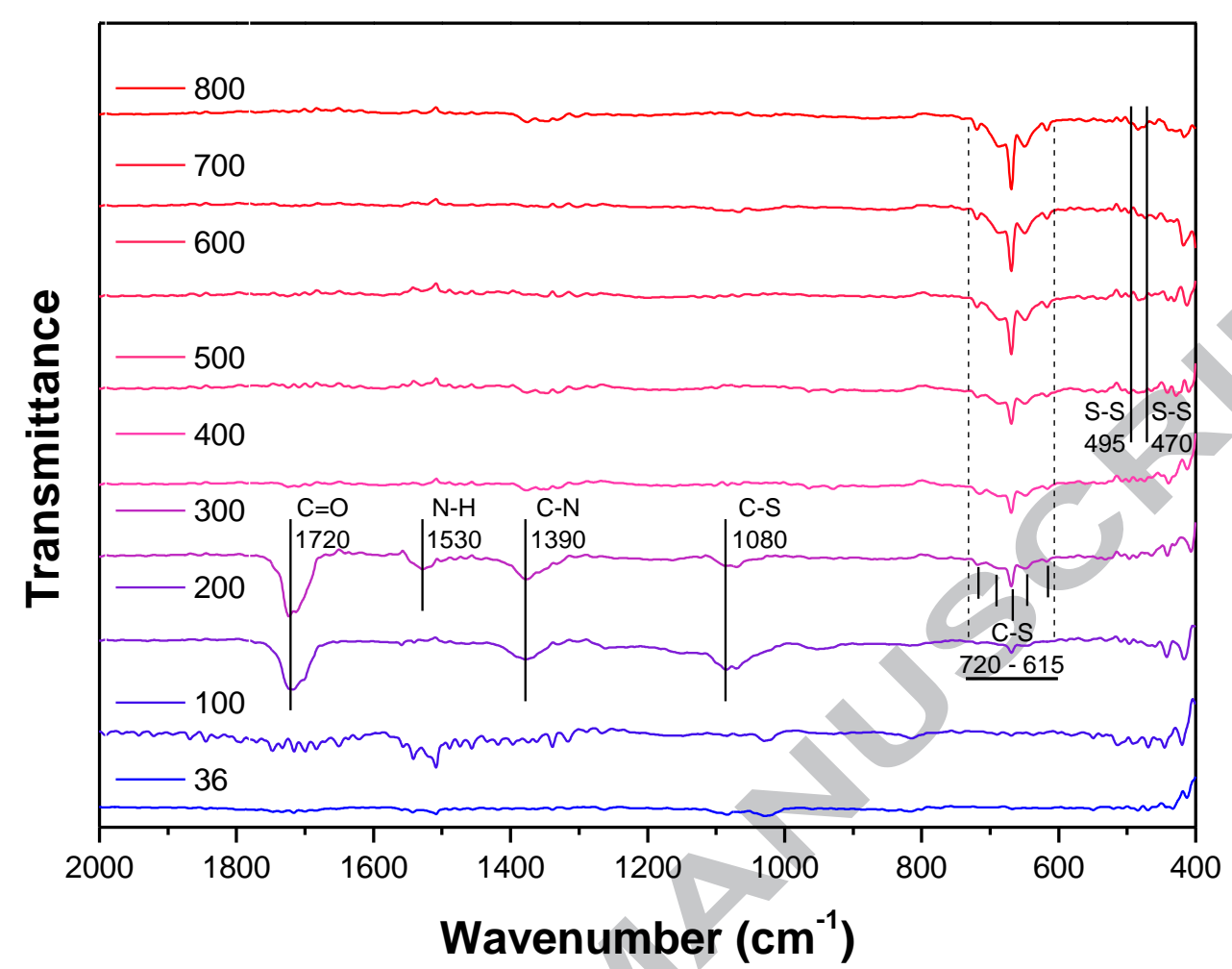

Figure 5. TGA-FTIR analysis of DiS-AC, plotted as a function of TGA analysis temperature (i.e. 36 $\left.800{ }^{\circ} \mathrm{C}\right)$. Peaks at $495 \mathrm{~cm}^{-1}$ and $470 \mathrm{~cm}^{-1}$ correspond to the $\mathrm{S}-\mathrm{S}$ disulfide bond. Peaks from $615 \mathrm{~cm}^{-1}$ to 720 $\mathrm{cm}^{-1}$ and $1080 \mathrm{~cm}^{-1}$ indicate typical organo-sulfur bonds. Peaks at $1390 \mathrm{~cm}^{-1}, 1530 \mathrm{~cm}^{-1}$, and $1720 \mathrm{~cm}^{-1}$ are representing $\mathrm{C}-\mathrm{N}, \mathrm{N}-\mathrm{H}$, and $\mathrm{C}=\mathrm{O}$ bonds, respectively.

Initially, at the ambient instrument analysis temperature (i.e. $36^{\circ} \mathrm{C}$ ), no discernible peak pattern is found in the spectra of the DiS-AC being analyzed; however, after overlooking the peaks stemming from water/humidity in the sample spectra at $100{ }^{\circ} \mathrm{C}$, starting at $200{ }^{\circ} \mathrm{C}$ the peaks in the spectra of the grafted polymer begin to emerge. Functional groups, including $\mathrm{C}=\mathrm{O}, \mathrm{N}-\mathrm{H}$, and $\mathrm{C}-\mathrm{N}$, can be detected at 1720, 1530, and $1390 \mathrm{~cm}^{-1}$, respectively. Evidence of the grafted polymer also appears in the FTIR spectra; around $200-300{ }^{\circ} \mathrm{C}$, the first peak for C-S is observed, as was also reported by Halas et al. (2010) [28]. Furthermore, a series of peaks attributed to the C-S bond are found in the range of $720-615 \mathrm{~cm}^{-1}$, typical of organo-sulfur compounds [29], that become more and more pronounced as the analysis temperature increases. Finally, although typically having an extremely weak signal in IR analysis [30], two very minor peaks corresponding to the S-S disulfide bond are observed at 495 and $470 \mathrm{~cm}^{-1}$ at the very high temperatures during analysis. 


\subsection{Kinetics of cadmium sorption for DiS-AC}

The trends of the sorption kinetics at three different initial concentrations $(0.2,0.35$, and $0.5 \mathrm{mg} / \mathrm{L})$ are comparable when normalized to the initial concentrations (Figure 6a). Hence, the lowest initial concentration of $0.2 \mathrm{mg} / \mathrm{L}$ was selected for kinetics fitting, using pseudo first-order kinetics (eq. 1) and pseudo second-order kinetics (eq. 2) (Figure 6b, c). Both kinetics models fit well with the data based on the correlation coefficient. Within 53 min of contact time, half of the initial cadmium was sorbed onto the DiS-AC at a loading of $2 \mathrm{~g} / \mathrm{L}$, while standard GAC reported in a similar adsorption study with a loading of $4 \mathrm{~g} / \mathrm{L}$ took 2.5 hours to reach half saturation [31]. To predict real-world performance of DiS-AC in an actual stormwater filter, the required amount of DiS-AC needed in one filter has been calculated based on industry specifications [32,33], and applied in the appropriate equations for sorption determination. Assuming that the rate of sorption increases proportionally to the dose of filtering (active sorption sites) material, the DiS-AC applied in realcolumn type packed filter will be expected to remove approximately $97 \%$ of cadmium within 10 seconds.
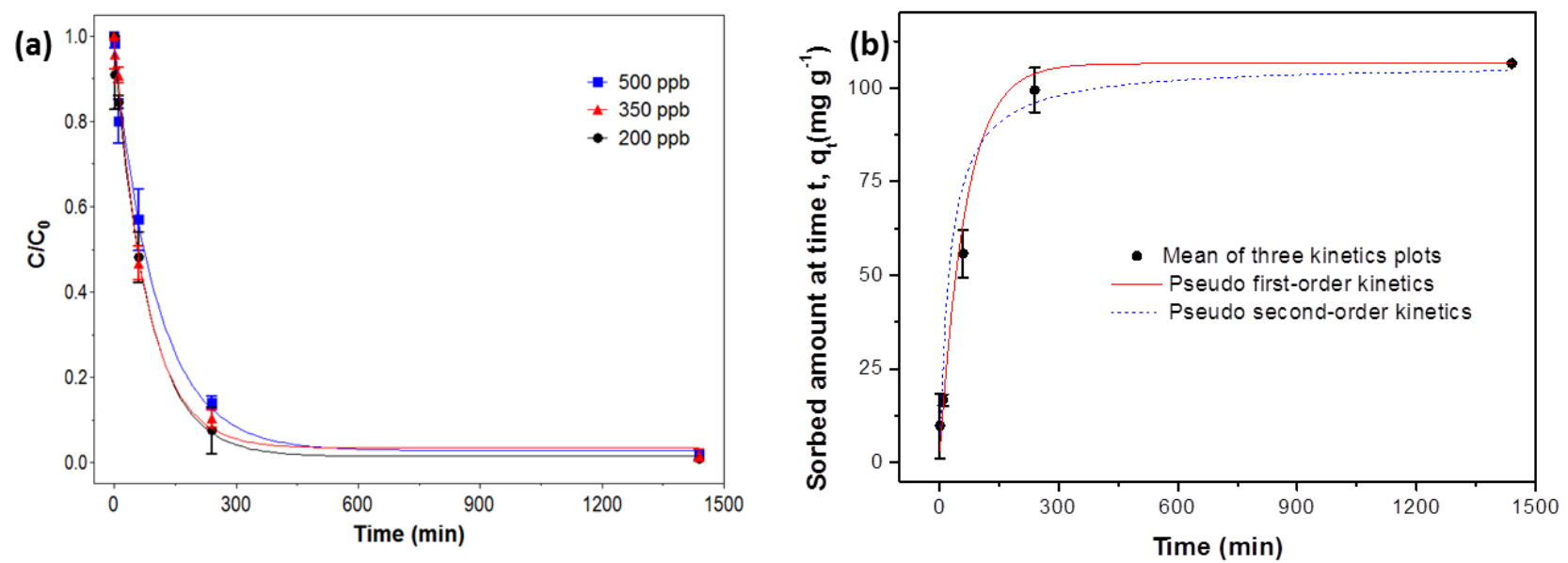

Figure 6. (a) Sorption kinetics for cadmium sorption to DiS-AC in batch experiments, with a DiS-AC loading of $2 \mathrm{~g} / \mathrm{L}$, examined at three initial cadmium concentrations and plotted using normalized $\mathrm{y}$-axes. (b) Pseudo first-order kinetics and pseudo second-order kinetics fittings for an initial cadmium concentration of $0.2 \mathrm{mg} / \mathrm{L}$. Error bars represent the standard deviation for replicates.

\subsection{Sorption isotherm and maximum capacity}


The Langmuir and Freundlich isotherms were fitted onto the cadmium sorption plots of DiS-AC (Figure 7). The parameters along with correlation coefficients are given in Table 2.

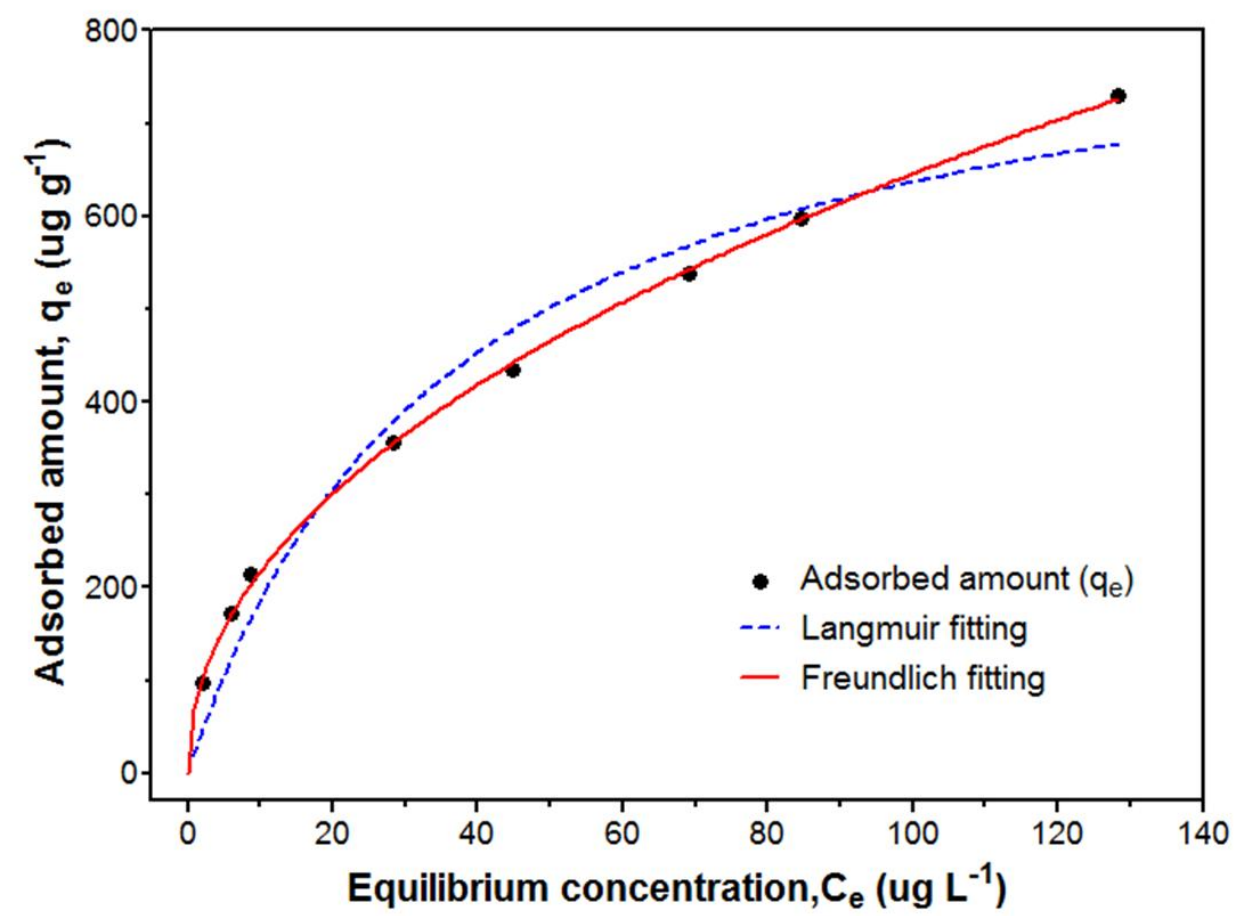

Figure 7. Sorption isotherms of cadmium ion sorption on disulfide-linked polymer grafted carbon substrates (DiS-AC). The red solid line represents the non-linear fitting of data by the Freundlich model, while the blue dashed line represents fitting by the Langmuir model.

The Freundlich fitting was found to be far better $\left(r^{2}=0.99\right)$ than the Langmuir fitting $\left(r^{2}=0.77\right)$ (SI, Figure A.1). The conformity with the Freundlich equation indicates that the DiS-AC is a multisite sorbent, in contrast to the Langmuir model that assumes a uniform surface [34]. This also points to the inherent randomness of how the grafted polymer adheres to the surface of the GAC. It is important to note that the present experiment focused only on trace amounts of cadmium, for particular relevance with stormwater runoff applications; hence, the plots only cover the region prior to the point where the plateau effect starts in the Langmuir isotherm. 
Table 2. Parameters corresponding to the Freundlich sorption isotherms and solid-water partitioning coefficients $\left(\mathrm{K}_{\mathrm{d}}\right)$ at a solution concentration of $0.35 \mathrm{mg} / \mathrm{L}$ for DiS-AC

\begin{tabular}{ccccc}
\hline & \multicolumn{3}{c}{ Freundlich } & \multirow{2}{*}{$\begin{array}{c}\mathbf{K}_{\mathbf{d}} \\
(\mathbf{L} / \mathbf{k g})\end{array}$} \\
\cline { 2 - 4 } & $\mathbf{K}_{\mathbf{F}}$ & $\mathbf{n}$ & $\mathbf{R}^{\mathbf{2}}$ & \\
\hline DiS-AC & 73 & 2.12 & 0.99 & $89.5 \cdot 10^{3}$ \\
\hline
\end{tabular}

The Freundlich constant, $\mathrm{K}_{\mathrm{F}}$, reflects the affinity of the sorbate [35]; and, with a $\mathrm{K}_{\mathrm{F}}$ of DiS-AC of $73\left[\left(\mathrm{mg} \mathrm{g}^{-1}\right)\left(\mathrm{mg}^{-1}\right)^{1 / \mathrm{n}}\right]$, this is roughly 50 times higher affinity compared to GAC and 174 times higher when compared to sand, both of which are commonly used for stormwater filtration [36,37] (SI, Table A.2). The heterogeneity and sorption favorability factor, $\mathrm{n}$, was calculated from the Freundlich fitting. The value $\mathrm{n}>1$ reflects sorption with a high affinity between the sorbate and the sorbent; therefore, in this study, DiS-AC has a value of $n=2.12$, indicating chemical sorption of cadmium [38][39]. The distribution coefficient $\left(\mathrm{K}_{\mathrm{d}}\right)$ of DiS-AC at a solution concentration of 0.35 $\mathrm{mg} / \mathrm{L}$ was $89 \cdot 10^{3} \mathrm{~L} / \mathrm{kg}$, which is 7.6 times higher compared to original GAC (SI, Table A.2).

\subsection{Effect of pH on cadmium sorption}

The sorption tests at different $\mathrm{pHs}$ have shown that DiS-AC efficiently retains cadmium in the $\mathrm{pH}$ range 6 - 8 (Figure 8 ). 


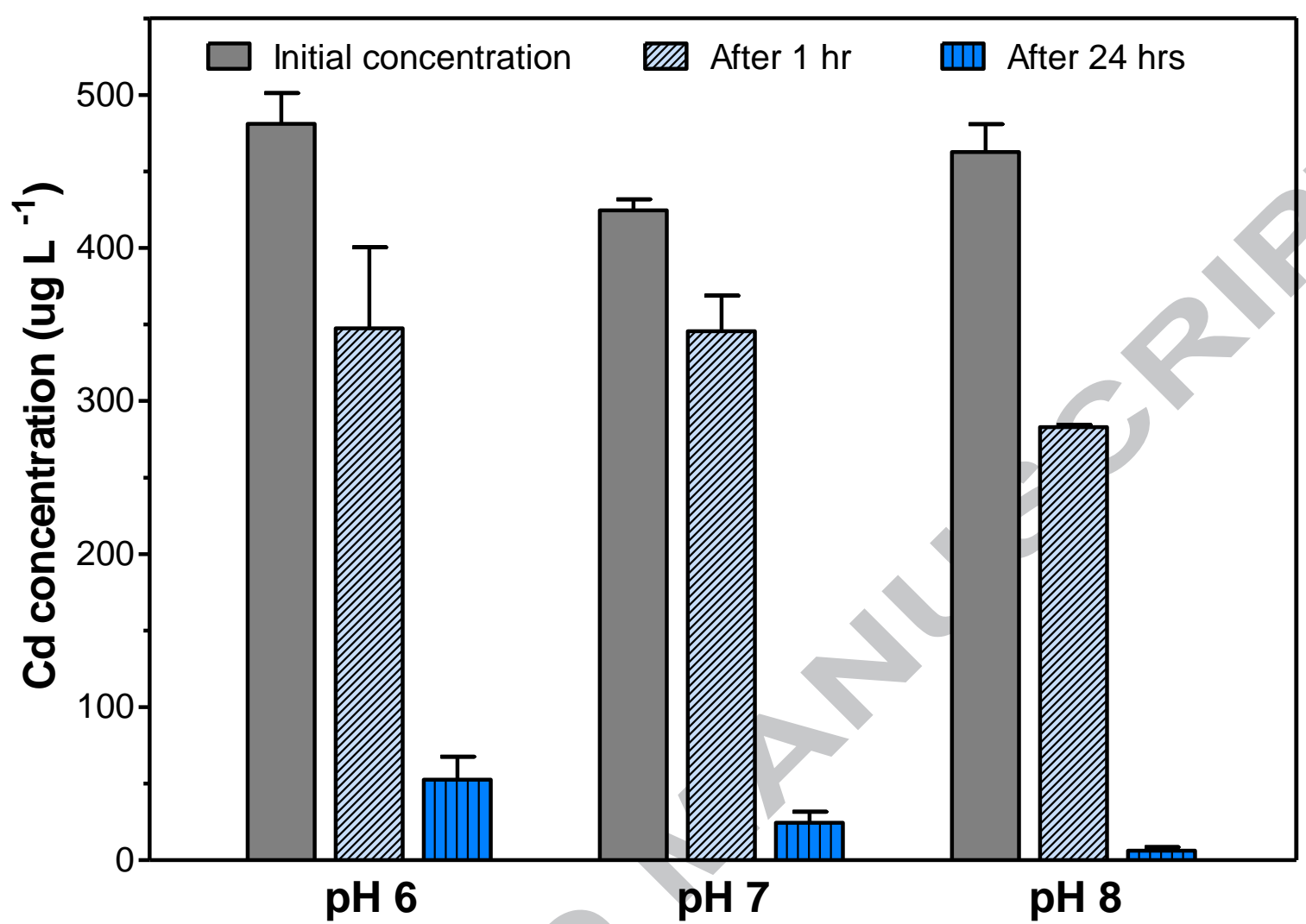

Figure 8. Effect of $\mathrm{pH}$ on the sorption of DiS-AC in batch experiments, with $2 \mathrm{~g} / \mathrm{L}$ sorbent dosage at 0.5 $\mathrm{mg} / \mathrm{L}$ cadmium solution concentration. Grey columns represent the initial concentration of cadmium, light blue columns represent the concentration after $1 \mathrm{~h}$ of reaction time, and dark blue columns represent the remaining cadmium concentration after $24 \mathrm{~h}$ of reaction time. The error bars represent the standard deviation for replicates.

At equilibrium and an initial cadmium concentration of $0.5 \mathrm{mg} / \mathrm{L}$, the removal percentages of cadmium were $89 \%, 94 \%$, and $99 \%$ at $\mathrm{pH} 6,7$, and 8 , respectively. The most effective sorption was revealed at a condition of $\mathrm{pH}=8$, with rapid sorption kinetics and higher capacity compared to other $\mathrm{pH}$ ranges. It is important to note that stormwater runoff in urban areas has fluctuating $\mathrm{pH}$ conditions within the ranges of $\mathrm{pH} 6-8$ [40]. Therefore, DiS-AC sorption could adequately work without any need for $\mathrm{pH}$ adjusting pre-treatment. Moreover, the sorption characteristics of DiS-AC, which are dependent on $\mathrm{pH}$ conditions, were in accordance with the sorption characteristics of the disulfide-linked polymer by itself [19].

\section{Conclusion}


A new type of carbon substrate covered with dangling thiol handles (DiS-AC) synthesized through acyl chlorination is suggested as a stormwater runoff filtration sorbent. Both physical and chemical characterization of the material confirmed that the polymer with thiol handles are successfully grafted and grown onto the surface of the amorphous carbon substrate. Based on cadmium sorption tests, DiS-AC exhibited a distribution coefficient of $89 \cdot 10^{3} \mathrm{~L} / \mathrm{kg}$ for sorbing cadmium, which is 37 times higher compared to conventional GAC sorbents. Furthermore, half of the trace amounts of cadmium ions were removed within an hour at a sorbent loading of $2 \mathrm{~g} / \mathrm{L}$. Additionally, applicability of the DiS-AC filter material at variable pHs between 6 and 8 , typical for stormwater runoff $\mathrm{pH}$, has been demonstrated. In conclusion, a novel material is introduced, which is a promising candidate for removing heavy metal contamination from stormwater runoff.

\section{Acknowledgments}

D.K., P.D.M., M.H.J., and H.R.A. acknowledge funding of this study from the Technical University of Denmark (DTU) through the KAIST-DTU Signature Project on Integrated Water Technology. C.T.Y. is grateful for the generous funding from National Research Foundation of Korea (NRF2017M3A7B4042235).

\section{Appendix A. Supporting information}

Figure A.1; Table A.1; Table A.2

\section{Reference}

[1] L.D. Sabin, H.L. Jeong, K.D. Stolzenbach, K.C. Schiff, Contribution of trace metals from atmospheric deposition to stormwater runoff in a small impervious urban catchment, Water Res. 39 (2005) 3929-3937. doi:10.1016/j.watres.2005.07.003.

[2] F. Clauson-Kaas, C. Ramwell, H.C.B. Hansen, B.W. Strobel, Ptaquiloside from bracken in stream water at base flow and during storm events, Water Res. 106 (2016) 155-162. 
doi:10.1016/j.watres.2016.09.049.

[3] Y.Y. Yang, G.S. Toor, Sources and mechanisms of nitrate and orthophosphate transport in urban stormwater runoff from residential catchments, Water Res. 112 (2017) 176-184. doi:10.1016/j.watres.2017.01.039.

[4] M. Gittleman, C.J.Q. Farmer, P. Kremer, T. McPhearson, Estimating stormwater runoff for community gardens in New York City, Urban Ecosyst. 20 (2017) 129-139. doi:10.1007/s11252-016-0575-8.

[5] K. Cederkvist, M.B. Jensen, P.E. Holm, Method for assessment of stormwater treatment facilities - Synthetic road runoff addition including micro-pollutants and tracer, J. Environ. Manage. 198 (2017) 107-117. doi:10.1016/j.jenvman.2017.04.097.

[6] V. Azzi, A. Kanso, V. Kazpard, A. Kobeissi, B. Lartiges, A. El Samrani, Lactuca sativa growth in compacted and non-compacted semi-arid alkaline soil under phosphate fertilizer treatment and cadmium contamination, Soil Tillage Res. 165 (2017) 1-10. doi:10.1016/j.still.2016.07.014.

[7] W. Jiao, W. Chen, A.C. Chang, A.L. Page, Environmental risks of trace elements associated with long-term phosphate fertilizers applications: A review, Environ. Pollut. 168 (2012) 4453. doi:10.1016/j.envpol.2012.03.052.

[8] H. Genç-Fuhrman, P.S. Mikkelsen, A. Ledin, Simultaneous removal of As , Cd , Cr , Cu , Ni and $\mathrm{Zn}$ from stormwater : Experimental comparison of 11 different sorbents, Water Res. 41 (2007) 591-602. doi:10.1016/j.watres.2006.10.024.

[9] T. Wium-andersen, A.H. Nielsen, T. Hvitved-, J. Vollertsen, Heavy metals, PAHs and toxicity in stormwater wet detention ponds, Novatech. (2010). 
[10] D. Schwartz, D.J. Sample, T.J. Grizzard, Evaluating the performance of a retrofitted stormwater wet pond for treatment of urban runoff, Environ. Monit. Assess. 189 (2017). doi:10.1007/s 10661-017-5930-6.

[11] G. Crini, Recent developments in polysaccharide-based materials used as adsorbents in wastewater treatment, Prog. Polym. Sci. 30 (2005) 38-70. doi:10.1016/j.progpolymsci.2004.11.002.

[12] A. Roy, J. Bhattacharya, A binary and ternary adsorption study of wastewater Cd(II), Ni(II) and Co(II) by r-Fe2O3 nanotubes, Sep. Purif. Technol. 115 (2013) 172-179. doi:10.1016/j.seppur.2013.05.010.

[13] W.S. Wan Ngah, M.A.K.M. Hanafiah, Removal of heavy metal ions from wastewater by chemically modified plant wastes as adsorbents: A review, Bioresour. Technol. 99 (2008) 3935-3948. doi:10.1016/j.biortech.2007.06.011.

[14] H.A. Patel, F. Karadas, A. Canlier, J. Park, E. Deniz, Y. Jung, M. Atilhan, C.T. Yavuz, High capacity carbon dioxide adsorption by inexpensive covalent organic polymers, J. Mater. Chem. 22 (2012) 8431-8437. doi:10.1039/c2jm30761h.

[15] H.A. Patel, F. Karadas, J. Byun, J. Park, E. Deniz, A. Canlier, Y. Jung, M. Atilhan, C.T. Yavuz, Highly stable nanoporous sulfur-bridged covalent organic polymers for carbon dioxide removal, Adv. Funct. Mater. 23 (2013) 2270-2276. doi:10.1002/adfm.201202442.

[16] H.A. Patel, S.H. Je, J. Park, Y. Jung, A. Coskun, C.T. Yavuz, Directing the structural features of N2-phobic nanoporous covalent organic polymers for $\mathrm{CO} 2$ capture and separation, Chem. Eur. J. 20 (2014) 772-780. doi:10.1002/chem.201303493.

[17] H.A. Patel, M.S. Yavuz, C.T. Yavuz, Exceptional organic solvent uptake by disulfide-linked 
polymeric networks, RSC Adv. 4 (2014) 24320. doi:10.1039/c4ra03355h.

[18] P.D. Mines, J. Byun, Y. Hwang, H.A. Patel, H.R. Andersen, C.T. Yavuz, Nanoporous networks as effective stabilisation matrices for nanoscale zero-valent iron and groundwater pollutant removal, J. Mater. Chem. A. 4 (2016) 632-639. doi:10.1039/C5TA05025A.

[19] D. Ko, J. Lee, H.A. Patel, M.H. Jakobsen, Y. Hwang, C.T. Yavuz, H.C.B. Hansen, H.R. Andersen, Selective removal of heavy metal ions by disulfide linked polymer networks, $\mathrm{J}$. Hazard. Mater. 332 (2017) 140-148. doi:10.1016/j.jhazmat.2017.03.007.

[20] X. Li, C. Bian, X. Meng, F. Xiao, Design and synthesis of an efficient nanoporous adsorbent for $\mathrm{Hg} 2+$ and Pb2+ ions in water, J. Mater. Chem. A Mater. Energy Sustain. 4 (2016) 59996005. doi:10.1039/C6TA00987E.

[21] P.D. Mines, D. Thirion, B. Uthuppu, Y. Hwang, M.H. Jakobsen, H.R. Andersen, C.T. Yavuz, Covalent organic polymer functionalization of activated carbon surfaces through acyl chloride for environmental clean-up, Chem. Eng. J. 309 (2017) 766-771. doi:10.1016/j.cej.2016.10.085.

[22] Z.M. Abou-Gamra, M.A. Ahmed, TiO2 nanoparticles for removal of malachite green dye from waste water, Adv. Chem. Eng. Sci. 5 (2015) 373-388. doi:10.4236/aces.2015.53039.

[23] Y.S. Ho, G. McKay, Pseudo-second order model for sorption processes, Process Biochem. 34 (1999) 451-465. doi:10.1016/S0032-9592(98)00112-5.

[24] J. Tolls, Sorption of veterinary pharmaceuticals in soils: A review, Environ. Sci. Technol. 35 (2001) 3397-3406. doi:10.1021/es0003021.

[25] A. Bhatnagar, W. Hogland, M. Marques, M. Sillanpää, An overview of the modification 
methods of activated carbon for its water treatment applications, Chem. Eng. J. 219 (2013) 499-511. doi:10.1016/j.cej.2012.12.038.

[26] D.G. Castner, K. Hinds, D.W. Grainger, X-ray photoelectron spectroscopy sulfur $2 p$ study of organic thiol and disulfide binding interactions with gold surfaces, Langmuir. 12 (1996) 5083-5086. doi:10.1021/la960465w.

[27] M. Descostes, F. Mercier, N. Thromat, C. Beaucaire, M. Gautier-Soyer, Use of XPS in the determination of chemical environment and oxidation state of iron and sulfur samples: constitution of a data basis in binding energies for Fe and $\mathrm{S}$ reference compounds and applications to the evidence of surface species of an oxidized py, Appl. Surf. Sci. 165 (2000) 288-302. doi:10.1016/S0169-4332(00)00443-8.

[28] N.J. Halas, J. Kundu, F. Le, P. Nordlander, H. Wang, Compositions for surface enhanced infrared absorption spectra and methods of using same, US 2010/0022020 A1, 2010.

[29] C.N.R. Rao, R. Venkataraghavan, T.R. Kasturi, Contribution to the infrared spectra of organosulphur compounds, Can. J. Chem. 42 (1964) 36-42.

[30] J.-M. Philias, B. Marsan, FTIR spectroscopic study and thermal and electrical properties of polymer electrolytes containing a cesium thiolate/disulfide redox couple, Electrochim. Acta. 44 (1999) 2351-2363. doi:https://doi.org/10.1016/S0013-4686(98)00357-0.

[31] D. Mohan, K.P. Singh, Single- and multi-component adsorption of cadmium and zinc using activated carbon derived from bagasse - an agricultural waste, Water Res. 36 (2002) 23042318.

[32] Contech Engineered Solutions LLC, Safety data sheet, Portland, OR 97220, 2017. 
[33] Contech Engineered Solutions LLC, Media cartridge filtration system drawing specifications, Portland, OR 97220, 2016.

[34] P. Hadi, M.H. To, C.W. Hui, C.S.K. Lin, G. McKay, Aqueous mercury adsorption by activated carbons, Water Res. 73 (2015) 37-55. doi:10.1016/j.watres.2015.01.018.

[35] B.H. Hameed, A.M. Din, A.L. Ahmad, Adsorption of methylene blue onto bamboo-based activated carbon: kinetics and equilibrium studies, J. Hazard. Mater. 141 (2007) 819-825. doi:10.1016/j.jhazmat.2006.07.049.

[36] J.J. Sansalone, Adsorptive infiltration of metals in urban drainage - Media characteristics, Sci. Total Environ. 235 (1999) 179-188. doi:10.1016/S0048-9697(99)00211-9.

[37] J.P. Chen, X. Wang, Removing copper, zinc, and lead ion by granular activated carbon in pretreated fixed-bed columns, Sep. Purif. Technol. 19 (2000) 157-167.

[38] S. Jodeh, N. Basalat, A. Abu Obaid, D. Bouknana, B. Hammouti, T.B. Hadda, W. Jodeh, I. Warad, Adsorption of some organic phenolic compounds using activated carbon from cypress products, J. Chem. Pharm. Res. 6 (2014) 713-723.

[39] H.K. Boparai, M. Joseph, D.M.O. Carroll, Kinetics and thermodynamics of cadmium ion removal by adsorption onto nano zerovalent iron particles, J. Hazard. Mater. 186 (2011) 458465. doi:10.1016/j.jhazmat.2010.11.029.

[40] H.A.C. Jeng, A.J. Englande, R.M. Bakeer, H.B. Bradford, Impact of urban stormwater runoff on estuarine environmental quality, Estuar. Coast. Shelf Sci. 63 (2005) 513-526. 


\section{Highlights}

- The novel disulfide polymer grafted activated carbon composites were devised.

- Covalent bonds between disulfide polymer and carbon substrate have been proven.

- DiS-AC showed rapid kinetics on removing heavy metal in overall range of pH 6 to 8 .

- DiS-AC showed high affinity towards even for trace amount of heavy metal in water. 
- GAC

Dis-AC

- Heavy metals (HM)
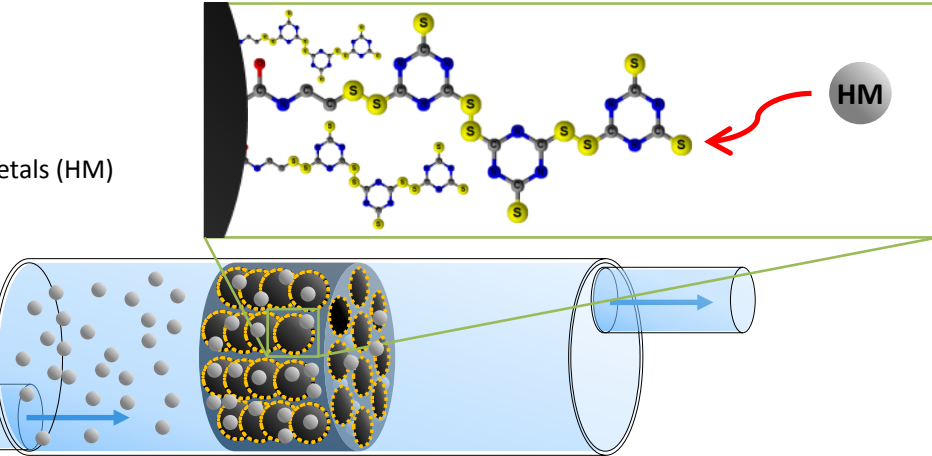